\title{
Non-Hodgkin's lymphoma. I: characterisation and treatment
}

\author{
Susan E O’Reilly, Joseph M Connors
}

This is the eighth in a series of articles examining recent developments in cancer
The non-Hodgkin's lymphomas are a heterogeneous collection of lymphoproliferative malignancies whose clinical behaviour, prognosis, and management vary widely according to histological subtype, stage, and bulk of disease. They are the seventh most commonly diagnosed malignancy. Typically patients present with localised or generalised lymphadenopathy. Common presenting findings are haematological cytopenias, drenching night sweats, unexplained fevers, or weight loss greater than $10 \%$ of baseline (B symptoms); hepatosplenomegaly, abdominal masses, or compression of internal organs such as the gastrointestinal tract, blood vessels, airways, spinal cord, ureters, or bile ducts; or localised tumours of parenchymal or visceral organs. Nevertheless, lymphoma may mimic virtually any other neoplasm.

Until about 25 years ago, most patients with nonHodgkin's lymphomas died of their disease. Although radiotherapy, single drug chemotherapy, and corticosteroid treatments were useful in palliating these patients, they were rarely curative. The advent of effective combination chemotherapy regimens, initially developed for Hodgkin's disease and subsequently applied to non-Hodgkin's lymphomas, resulted in the cure of advanced tumours in a few patients with lymphoma.' Similarly, improvements in histological subclassification, diagnostic radiology, radiation therapy, and general supportive care, especially in treating infectious complications of lymphomas, have all contributed to a better understanding of the nature of lymphomas and clearer planning of management of these disorders. More recently, developments in molecular biology of oncogenesis have begun to reveal the aetiological events in their development. ${ }^{2}$

\section{Histological classification}

Optimal management of non-Hodgkin's lymphomas must be based on a clear understanding of the cell pathology, the staging, and clinical course of the various subtypes. A more detailed understanding of the prognostic factors influencing the course of lymphomas is also helpful in planning treatment. Several different histological classifications are used throughout the world, resulting in confusion and difficulty in comparing data from different centres. The working formulation for classifying lymphomas provides a comprehensive system which focuses on reproducing characteristics identifiable by light microscopy. It combines the most reproducible histological features in several classification schemes into a system allocating the lymphomas to 10 different subtypes, and it also provides a cross reference to other systems. ${ }^{3}$ In the working formulation lymphomas are assigned to three categories - low, intermediate, and high gradebased on the natural course of these diseases, as modified by the best treatment available in the ' 60 s and '70s.

The working formulation does not take into account the more detailed information now available on immunological phenotyping, which is based on specific cell membrane and cytoplasmic antigen testing and various DNA probe information. Such techniques are providing increasing insight into the molecular biological origin of lymphomas and have shown that the follicular (nodular) lymphomas are almost exclusively of B cell origin and that lymphoblastic lymphoma and mycosis fungoides typically arise from $\mathrm{T}$ cells. Diffuse lymphomas may arise from B or $\mathrm{T}$ cells or may be of indeterminate origin. We have used the working formulation terminology throughout this review (table I).

Developments in immunology, monoclonal antibody probes, cytogenetics, and characterisation of oncogenes and growth factors will continue to expand our understanding of lymphomas. And these added insights into lymphoma classification may eventually translate into improved treatments. Nevertheless, despite the increasing sophistication of the molecular biologists and pathologists most clinical decisions are based on light microscopy. An experienced haematopathologist can regularly and reproducibly distinguish between follicular (nodular) and diffuse lymph node disease and between small and large lymphocytes. It is usually relatively straightforward to distinguish the uncommon special lymphomas: small non-cleaved cell (Burkitt's and non-Burkitt's) and $T$ cell lymphoblastic lymphomas. In addition, haematopathologists can discriminate between the true lymphomas and lymphoma-like conditions such as sarcoidosis, syphilis, pseudolymphomas, and lymphadenopathy related to HIV, as well as rare conditions such as lymphomatoid

Box 1-Staging procedures for malignant lymphomas

\section{Mandatory procedures}

History and physical examination

Biopsy of diagnostic tissue

Laboratory profile:

Complete blood count, liver and renal function tests, serum calcium concentration, serum protein electrophoresis

Chest radiographs

Computed tomography of abdomen and pelvis

Bone marrow aspiration and biopsy

Upper gastrointestinal series, small bowel follow through for all ear, nose, and throat lymphomas (in $20 \%$ of such lymphomas there is gastrointestinal disease)

Ear, nose, and throat examination (to visualise Waldeyer's ring, nasopharynx) in all gastrointestinal lymphomas

\section{Optional procedures}

Lymphangiography (only if result will alter treatment) Cytology of cerebrospinal fluid in high risk patients: Small non-cleaved and lymphoblastic tumours Large cell tumour with marrow or sinus disease Patients with neurological abnormalities

Cytology of pleural or peritoneal effusions

Computed tomography or radiography of symptomatic sites

Bone scanning (if pain present)

Laparotomy recommended for:

Diagnosis of abdominal mass

Resection of gastrointestinal lymphoma
Mead.

$B M \mathcal{F} 1992 ; 304: 1682-6$ 


\section{Box 2-Ann Arbor staging classification for Hodgkin's disease}

Stage I

Single lymph node region affected or single extralymphatic organ or site

StageII

Two or more lymph node regions affected on the same side of the diaphragm with or without localised disease in extralymphatic site (IIIE)

Stage III

Lymph node regions affected on both sides of the diaphragm with or without localised disease of an extralymphatic organ or site (IIIE) or spleen (IIIS), or both (IIISE)

Stage IV

Diffuse or disseminated disease in one or more extralymphatic organs, with or without associated lymph node disease

Subtype A-Asymptomatic

Subtype B-Patient has constitutional symptoms: Fever, night sweats, or weight loss $>10 \%$ of baseline

granulomatosis, angioimmunoblastic lymphadenopathy, Wegener's granulomatosis, and lethal midline granuloma.

The prognostic and therapeutic implications of more recently defined entities such as intermediate cell lymphoma and its follicular variant, mantle zone lymphoma, ${ }^{+}$and peripheral $\mathrm{T}$ cell lymphoma (the commonest non-cutaneous $\mathrm{T}$ cell lymphoma) ${ }^{5}$ are unclear at present and await more complete description and analysis. With current treatment techniques pathologists need only separate the lymphomas into three main therapeutic groups - low grade, aggressive (comprising the large cell lymphomas and immunoblastic lymphoma), and a special category (Burkitt's and non-Burkitt's small non-cleaved cell lymphoma and $\mathrm{T}$ cell lymphoblastic lymphoma) to allow the clinician to plan treatment (table I). For planning treatment, immunoblastic lymphoma is best included in the same category as diffuse large cell lymphoma despite its assignment to the high grade group in the diagnosis, distribution of stages, and natural course after treatment of different lymphomas are also summarised in table $\mathrm{I}^{3}$

\section{Staging}

Staging has an important role in assigning prognosis and planning treatment in any patient with malignant working formulation. The incidence, median age at

lymphoma. Although the extent and duration of staging investigations may have to be modified in urgent situations or in frail patients, all other patients should undergo the mandatory procedures and any clinically indicated optional procedures listed in box 1 . The most commonly used staging system is that of the Ann Arbor Conference (box 2). ${ }^{6}$ This system was originally devised for Hodgkin's disease, a slowly progressive disease that tends to advance in an orderly fashion to contiguous, usually nodal structures. Malignant lymphomas, on the other hand, usually occur in elderly people, often progress early to distant nodal or extranodal sites, and may evolve rapidly. Therefore, the Ann Arbor staging system is not as useful a predictor of treatment outcome in malignant lymphoma as in Hodgkin's disease. As a consequence, a simple staging system based on anatomic extent of disease, tumour bulk, and constitutional symptoms is adequate for initial clinical decision making. This system is based on the Ann Arbor staging system plus information about the patient's age and bulk of disease (box 3) and applies to a wide range of presentations of lymphoma.

Once a pathologist has reviewed a biopsy specimen from a lymph node or extranodal site affected by lymphoma and clinical staging has been completed as described above, patients can be classified for treatment according to histology, extent of disease, and age. Table II gives guidelines for an overall approach to management.

\section{Low grade lymphomas}

About $40 \%$ of lymphomas encountered in North America and western Europe are low grade. Box 4 shows their characteristics. These lymphomas typically present insidiously, often with progressive lymphadenopathy, which may wax and wane or with cytopenias, hepatosplenomegaly, or compression of ureters, veins, or bile ducts. Patients usually do not have typical B symptoms. Careful staging is worth while to identify the minority of patients who have

\section{Box 3-Simplified staging system for clinical decision making}

$\begin{array}{ll}\text { Limited stage } & \text { Advanced stage } \\ \text { Ann Arbor stage I or II } & \text { Ann Arbor stage III or IV } \\ \text { and } & \text { or } \\ \text { Absence of B symptoms } & \text { Presence of B symptoms } \\ \quad \text { and } & \text { or } \\ \text { Largest tumour diameter } & \text { Mass }>10 \mathrm{~cm} \\ \quad<10 \mathrm{~cm} & \end{array}$

TABLE I-Correlation of the working formulation for classifying malignant lymphoma with treatment oriented approach. Clinical characteristics are derived from working formulation

\begin{tabular}{|c|c|c|c|c|c|c|c|c|c|}
\hline \multirow[b]{2}{*}{ Working formulation } & \multirow{2}{*}{$\begin{array}{l}\text { Treatment- } \\
\text { oriented } \\
\text { approach }\end{array}$} & \multirow{2}{*}{$\begin{array}{l}\text { Relative } \\
\text { frequency } \\
(\%)\end{array}$} & \multirow{2}{*}{$\begin{array}{l}\text { Median age } \\
\text { at diagnosis } \\
\text { (years) }\end{array}$} & \multicolumn{2}{|c|}{ Stage at diagnosis (\%) } & \multirow{2}{*}{$\begin{array}{l}\text { Male: femalet } \\
\text { ratio }\end{array}$} & \multirow{2}{*}{$\begin{array}{c}\% \text { With } \\
\text { bone marrow } \\
\text { disease }\end{array}$} & \multirow{2}{*}{$\begin{array}{c}\text { Median } \\
\text { survival } 6 \\
\text { years }\end{array}$} & \multirow{2}{*}{$\begin{array}{c}\text { \% Surviving } \\
5 \text { years }\end{array}$} \\
\hline & & & & $\mathrm{I} / \mathrm{II}$ & III/IV & & & & \\
\hline Low grade & \multirow[t]{4}{*}{ Low grade } & & & & & & & & \\
\hline A-Small, lymphocytic & & 4 & 60 & 11 & 89 & $1 \cdot 2$ & 71 & $5 \cdot 8$ & 59 \\
\hline $\begin{array}{l}\text { B-Follicular, small } \\
\text { cleaved }\end{array}$ & & 23 & 54 & 18 & 82 & $1 \cdot 3$ & 51 & $7 \cdot 2$ & 70 \\
\hline $\begin{array}{l}\text { C-Follicular, mixed } \\
\text { large and small cleaved }\end{array}$ & & 8 & 56 & 27 & 73 & $0 \cdot 8$ & 30 & $5 \cdot 1$ & 50 \\
\hline Intermediate grade & \multirow[t]{5}{*}{ Aggressive } & & & & & & & & \\
\hline D-Follicular, large & & 4 & 55 & 27 & 73 & 1.8 & 34 & $3 \cdot 0$ & 45 \\
\hline $\begin{array}{l}\text { E-Diffuse, small } \\
\text { cleaved }\end{array}$ & & 7 & 58 & 28 & 72 & 1 & 32 & $3 \cdot 4$ & 33 \\
\hline $\begin{array}{l}\text { F-Diffuse, mixed } \\
\text { large and small cleaved }\end{array}$ & & 7 & 58 & 45 & 55 & $1 \cdot 1$ & 14 & $2 \cdot 7$ & 38 \\
\hline $\begin{array}{l}\text { large and small cleaved } \\
\mathrm{G} \text {-Diffuse, large }\end{array}$ & & 20 & 57 & 46 & 54 & 1 & 10 & $2 \cdot 7$ & 38 \\
\hline \multirow{2}{*}{$\begin{array}{l}\text { High grade } \\
\text { H-Immunoblastic }\end{array}$} & \multirow{4}{*}{ Special } & 8 & & 52 & 48 & 1.5 & 12 & 1.3 & 32 \\
\hline & & 8 & 31 & 32 & 48 & 1.5 & 12 & 1.3 & 32 \\
\hline $\begin{array}{l}\text { I-Lymphoblastic } \\
\text { J-Small, non cleaved }\end{array}$ & & $\begin{array}{l}4 \\
5\end{array}$ & $\begin{array}{l}17 \\
30\end{array}$ & $\begin{array}{l}27 \\
34\end{array}$ & $\begin{array}{l}73 \\
66\end{array}$ & 2 & 50 & $\begin{array}{l}2 \cdot 0 \\
0 \cdot 7\end{array}$ & 26 \\
\hline J-Small, non cleaved & & & & 34 & 66 & $2 \cdot 6$ & 14 & 87 & 23 \\
\hline
\end{tabular}




\begin{tabular}{|c|c|c|c|c|}
\hline Category & Histology & Stage & $\begin{array}{c}\text { Age } \\
\text { (years) }\end{array}$ & Treatment \\
\hline \multirow[t]{2}{*}{ Low grade } & $\begin{array}{l}\text { Small, lymphocytic } \\
\text { Follicular, small } \\
\text { cleaved }\end{array}$ & Limited & All & Radiation of affected site \\
\hline & Follcular, mixed & Advanced & All & $\begin{array}{l}\text { Observation if asymptomatic and without } \\
\text { threatening disease } \\
\text { Single drug chemotherapy if gradual response } \\
\text { sufficient } \\
\text { Multi-drug chemotherapy if rapid response } \\
\text { necessary } \\
\text { Local irradiation for focally troublesome disease } \\
\text { Enrolment on aggressive experimental protocols }\end{array}$ \\
\hline \multirow[t]{3}{*}{ Aggressive } & $\begin{array}{l}\text { Diffuse, small } \\
\text { cleaved } \\
\text { Diffuse, mixed }\end{array}$ & Limited & All & $\begin{array}{l}\text { Brief chemotherapy and irradiation of affected } \\
\text { site }\end{array}$ \\
\hline & Follicular, large & & $<70$ & Frequency of dose intensive chemotherapy \\
\hline & $\begin{array}{l}\text { Diffuse, large } \\
\text { Immunoblastic }\end{array}$ & Advanced & $\geqslant 70$ & $\begin{array}{l}\text { Chemotherapy modified to maximum tolerable } \\
\text { toxicity }\end{array}$ \\
\hline Special & $\begin{array}{l}\text { Lymphoblastic } \\
\text { Small non-cleaved }\end{array}$ & All & $<60$ & $\begin{array}{l}\text { High dose intensive chemotherapy with central } \\
\text { nervous system chemoprophylaxis }\end{array}$ \\
\hline & & & $\geqslant 60$ & Palliative chemotherapy and irradiation \\
\hline
\end{tabular}

limited stage disease in whom radiation of the affected site may be curative. Up to $50 \%$ of patients with limited stage disease (I or IIA, low bulk) will achieve long term freedom from disease, although whether they have been cured or will have late relapses remains to be established.' In most patients with low grade lymphoma who have advanced stage disease, management is determined by the severity of symptoms and the degree to which organs are compromised. Traditionally, asymptomatic patients with normal blood counts, no actual or imminent organ compromise, and no cosmetically unacceptable masses may be observed safely until symptomatic or threatening disease develops. Local problems can often be dealt with by irradiation. Systemic problems merit chemotherapy, the choice of which depends on the urgency with which a response must be achieved.

\section{NON-URGENT RESPONSE}

If it is not necessary to obtain a rapid response, oral chlorambucil or cyclophosphamide with or without prednisone is the best treatment. The main side effect with this approach is cumulative marrow suppression, especially if treatment is given daily, but treatment is usually well tolerated. Prednisone can be a useful treatment initially, but prolonged use is best avoided because of its side effects, which can be cumulative and troublesome, particularly in elderly patients.

When oral chemotherapy is used the white blood cell count must be monitored regularly. If it remains in the normal range the dose of the drug should be increased to ensure that a sufficient amount is being absorbed. Oral therapy should not be deemed ineffective until the dose delivered is capable of causing mild myelosuppression.

Prednisone should be used alone for treating patients with severe anaemia, myelosuppression, or thrombocytopenia due to a packed marrow or immune destruction. A reasonable dose is $40 \mathrm{mg} / \mathrm{m}^{2}$ daily. An alkylating drug such as chlorambucil or cyclophosphamide can be cautiously introduced after an initial response and prednisone gradually reduced.

Cytopenias related to immune destruction may be encountered in diffuse small lymphocytic lymphoma (which has a clinical course similar to that of chronic lymphatic leukaemia), or occasionally other diffuse lymphomas, but are rarely seen in the follicular lymphomas.

\section{URGENT RESPONSE}

If a rapid response is needed in an advanced low grade lymphoma then combination chemotherapy is indicated. Since these lymphomas are very responsive to alkylating agents, combinations including cyclophosphamide, vincristine, and prednisone with or without additional drugs are popular and reasonable (table II). Patients should be treated until a sustained complete response or stabilisation is achieved.

Radiotherapy is a useful adjunct to the palliative treatment of low grade lymphomas. The extent of disease should dictate whether radiotherapy is of only the affected site or of an extended field. The decision to use wide field radiotherapy must be balanced against the potential for the associated myelosuppression to compromise later delivery of systemic chemotherapy.

EXPERIMENTAL TREATMENT OF ADVANCED STAGE LOW GRADE LYMPHOMA

Low grade lymphoma is a chronic disease which in the past had a median survival of eight to 10 years but inevitably proved fatal. It remains difficult to manage, especially in younger patients. Several experimental programmes are evaluating the benefit of aggressive treatment after diagnosis in younger patients. ${ }^{8-11}$ Some centres offer newly diagnosed patients autologous or allogeneic bone marrow transplantation immediately after diagnosis. At the British Columbia Cancer Agency newly diagnosed patients with advanced stage disease are offered an experimental protocol comprising 12 weeks of intensive outpatient chemotherapy followed by radiotherapy to all originally affected lymph nodes. ${ }^{12}$ The National Cancer Institute treats such patients with multidrug chemotherapy and radiotherapy. ${ }^{11}$ All of these studies show an initial improvement in disease free survival and freedom from further treatment for low grade lymphoma, but longer follow up will be needed to establish whether patients are cured of their disease or whether disease free survival or overall survival is improved by early aggressive intervention. Until these experimental programmes have longer term results the conventional management of low grade lymphomas described earlier in this paper remains the standard.

\section{Limited stage large cell lymphoma}

As defined previously, limited stage disease includes Ann Arbor stage I or II disease, a tumour mass $<10 \mathrm{~cm}$, and the absence of B symptoms. Historically, these patients were treated with only radiotherapy; however, the reported cure rate with such local treatment varied between $25 \%$ and $75 \%$ but averaged less than $50 \% .^{13-15}$

Since combination chemotherapy cures advanced disease it seemed reasonable to use the initial manage-

\section{Box 4-Clinical characteristics of lymphomas}

Low grade

Aggressive histology

Patients' median age 55 Patients' median age 55 to 60 years (rarely $<40$ ) years

Indolent disease with Firm, fixed lymph nodes median survival $\geqslant 7$ Potentially curable years Invasion of adjacent

Limited stage $(10 \%)-$ tissues potentially curable Often affects unusual Advanced stage $(90 \%)-$ extranodal structures, currently incurable

Do not usually invade adjacent soft tissue

Do not usually invade central nervous system, testes

Bone marrow disease in $50 \%$ of cases 
ment of early stage disease. ${ }^{16-20}$ The advantage of this approach is that the chemotherapy can be quite brief, lessening the disruption of the patient's life and minimising cumulative side effects. Most importantly, the chemotherapy is given when it is most likely to be effective, rather than late in the disease course when the tumour has had time to evolve clones of drug resistant cells.

The current recommendations for limited stage disease are that patients receive combination chemotherapy with or without irradiation of the affected site. During 1980-4 Connors et al treated 78 patients with three cycles of chemotherapy with cyclophosphamide, doxorubicin, vincristine, and prednisone (CHOP) plus irradiation of affected sites. ${ }^{21}$ This well tolerated regimen cured more than $80 \%$ of these patients. The approach has been refined to six weeks of weekly chemotherapy with doxorubicin, cyclophosphamide, vincristine, bleomycin, and prednisone (ACOB), with similar results. ${ }^{22}$ The excellent outcome with such brief chemotherapy means that it is the optimal treatment irrespective of age in patients with early stage disease. It is uncertain whether radiotherapy adds to the overall outcome, as no trials have yet been published.

\section{Advanced stage, aggressive histology (large cell) lymphomas}

Lymphomas with aggressive histology (follicular large, diffuse cleaved, non-cleaved, diffuse mixed, and immunoblastic lymphomas) comprise about $40 \%$ of all lymphomas (box 4). This group of large cell lymphomas is highly responsive to combination chemotherapy and a proportion of all patients may be cured with this treatment. Early regimens developed for treating Hodgkin's disease, such as mustine, vincristine, procarbazine, and prednisone (MOPP), resulted in the first reported cures of advanced stage diffuse large cell lymphoma. ${ }^{2324}$ Subsequently, the addition of doxorubicin proved highly effective in obtaining complete responses in these lymphomas. Studies of the CHOP regimen have reported a $30 \%$ overall 10 year survival in advanced stage disease. ${ }^{2526}$ Other first generation combinations have produced similar results. Many different regimens have since been developed which give more intensive treatment and additional drugs. Toxicity is increased, particularly from infection, but it remains unclear whether the efficacy of treatment is improved. Several regimens have been reported to improve survival in single institution studies, ${ }^{27-30}$ and randomised clinical trials to evaluate the relative effectiveness of these different regimens are ongoing or recently completed. The results of well designed large randomised studies will be important in determining management of aggressive histology lymphomas in the 1990s. For the present, in view of the persisting controversy over which is the best treatment approach, we recommend that clinicians select the regimen with which they feel most comfortable and in which they have the most confidence and that it is used in maximally tolerated doses.

\section{Prognostic factors in diffuse large cell lymphoma}

Several studies of prognostic factors for outcome have been published. In particular, data from Coiffier et al ${ }^{31}$ Shipp et al, ${ }^{32}$ Jagannath et al, ${ }^{33}$ and Hoskins et $a l,{ }^{34}$ have pointed to a constellation of factors which predict an adverse prognosis. In aggregate these factors include age over 60 , a poor performance status, a lactate dehydrogenase concentration greater than three times normal, tumour bulk $>10 \mathrm{~cm}$, the presence of B symptoms, disease of two or more extranodal sites, multiple nodal sites affected, and various other less common factors such as a low serum albumin concentration. Various formulas to predict which patients will fail are now being developed and more intensive treatments with either bone marrow transplantation protocols or intensive chemotherapy with cytokine support will probably be designed to treat patients young enough to withstand more aggressive treatment who have a predictably poor outcome with current standard chemotherapy regimens. One of the challenges facing lymphoma specialists in the next 10 years is to define the precise subgroups of patients in whom such treatment is indicated and then to develop modifications of current treatment programmes and prove whether they result in a better outcome.

1 Lowenbraun S, DeVita VT, Serpick AA. Combination chemotherapy with nitrogen mustard, vincristine, procarbazine, and prednisone in lymphonitrogen mustard, vincristine, procarbazine, and predni

2 Weinberg RA. Oncogenes and the mechanisms of carcinogenesis. Sci Am 1987;12(2):1

3 National Cancer Institute. Sponsored study of classification of non-Hodgkin's lymphomas. Summary and description of a working formulation for clinica usage. Cancer 1982;49:2112.

4 Weisenburger DD, Kim H, Rappaport H. Mantle zone lymphoma: a follicular variant of intermediate lymphoma. Cancer 1982;49:2112.

5 Greer JP, York JC, Cousar JB Mitchel RT, Flexner JM, Collins RD, et al. Peripheral $\mathrm{T}$ cell lymphoma: a clinicopathologic study of 42 cases. 7 Clin Oncol 1984;2:7.

6 Carbone PP, Kaplan HS, Musshoff K, Smithers DW, Tubiana M. Report of the committee on Hodgkin's disease staging classification. Cancer Res 1971;31:1860.

7 Gospodarowicz MK, Bush RS, Brown TC, Chua TC. Prognostic factors in nodular lymphomas: a multivariate analysis based on the Princess Margaret Hospital experience. Int $f$ Rad Oncol Biol Phys 1984;10(4):489.

8 Glick JH, Barnes JM, Ezdinli EZ, Berard CW, Orlon EL, Bennett JM. Nodular mixed lymphoma: results of a randomized trial failing to confirm prolonged disease-free survival with COPP chemotherapy. Blood 1981;58: 920

9 Longo DL, Young RC, Hubbard SM, Wesley M, Fisher RL, Jaffe E, et al. Prolonged initial remission in patients with nodular mixed lymphoma. Ann Intern Med 1984;100:651.

10 McLaughlin P, Fuller LM, Velasquez WS, Butler JJ, Hagemeister FB, Sullivan-Holley JA, et al. Stage III follicular lymphoma: durable remissions with a combined chemotherapy-radiotherapy regimen. 7 Clin Oncol 1987;5: 867

11 Young RC, Longo DL, Glatstein E, Matis LA, Ostchega Y, Nanfro J, et al. Watchful-waiting (WW) $v$ aggressive combined modality therapy $(\mathbf{R x})$ in the treatment of Stage III-IV indolent non-Hodgkin's lymphoma [abstract]. treatment of Stage IIr-IV indolent non-Hodgkin's lymphoma abs
Proceedings of the American Society of Clinical Oncology 1987;6:A790.

12 Klasa RJ, Hoskins PJ, O'Reilly SE, Fairey R, Voss N, Gascoyne R. et al. BP-VACOP and extensive lymph node irradiation $\left(R^{T}\right)$ for advanced stage low grade lymphoma. Proceedings of the American Society of Clinical Oncology low grade lym

13 Jones SE, Fuks Z, Kaplan HS, Rosenberg SA. Non-Hodgkin's lymphomas. V. Rsults of radiotherapy. Cancer 1973;32:682.

14 Vokes EE, Ultmann JE, Golomb HM, Gaynor ER, Ferguson DJ, Griem $M L$, et al. Lonterm survival of patients with localized diffuse histiocytic lymphoma. J Clin Oncol 1985;3:1309.

15 Levitt SH, Lee CKK, Bloomfield CD, Frizzera G. The role of radiation therapy in the treatment of early stage large cell lymphoma. Hematol Oncol 1985;3:33.

16 Nissen NI, Ersboll J, Hansen HS, Walbom-Jorgensen S, Pederson-Bjergaard $\mathrm{J}, \mathrm{Hansen} \mathrm{HM}$, et al. A randomized study of radiotherapy versus radiotherapy plus chemotherapy in stage I-II non-Hodgkin's lymphomas. Cancer 1983; plus ch.

17 Landberg TG, Hakansson LG, Moller TR, Mattisson WKI, Landys KE, Johansson BG, et al. CVP remission maintenance in stage I or II nonHodgkin's lymphomas: preliminary results of a randomised study. Cancer Hodgkin's ly

18 Monfardini S, Banfi A, Bonadonna G, Rilke F, Milani F, Valagussa P, et al. Improved five year survival after combined radiotherapy-chemotherapy for stage I-II non-Hodgkin's lymphomas. Int I Radial Oncol Biol Phys 1980;6:125

19 Miller TP, Jones SE. Initial chemotherapy for clinically staged localized nonHodgkin's lymphomas of unfavorable histology. In: Ford RJ, Fuller LM, Hagenmeister FB, eds. Hodgkin's disease and non-Hodgkin's lymphoma: new perspectives in immunopathology, diagnosis and treatment. New York: Raven Press, 1984:33-9.

20 Cabanillas F. Chemotherapy as definitive treatment of stage I-II large cell and diffuse mixed lymphomas. Hematol Oncol 1985;3:25.

21 Connors JM, Klimo P, Fairey RN, Voss N. Brief chemotherapy and involved field radiation therapy for limited stage aggressive histology lymphoma. Ann Intern Med 1987:107:25.

22 Connors JM, Fairey R, Klimo P, O'Reilly S, Voss N. ACOB: 6-week chemotherapy and involved field radiotherapy (IFRT) for limited stage large chemotherapy and involved field radiotherapy (IFRT) for limited stage large Oncology. 1988;7:224.

23 Luce JK, Gamble JF, Wilson HE, Monto RN, Isaacs BL, Palmer RL, et al. Combined cyclophosphamide, vincristine and prednisone therapy of malignant lymphoma. Cancer 1971;28:306.

24 Bagley CM, DeVita VT Jr, Berard CW, Canellos GP. Advanced lymphosarcoma: intensive cyclical combination chemotherapy with cyclophosphamide, vincristine and prednisone. Ann Intern Med 1972;76:227.

25 Armitage JO, Fyfe MAE, Lewis J. Long-term remission durability and functional status of patients treated for diffuse histiocytic lymphoma with the CHOP regimens. $f$ Clin Oncol 1984;2:898.

26 Coltman CA Jr, Dahlberg S, Jones SE. CHOP is curative in thirty percent of patients with large cell lymphoma: a twelve year Southwest Oncology of patients with large cell Group follow up. In: Skarin AT, ed. Update on.

27 Skarin AT, Canellos GP, Rosenthal DS, Case DC, MacIntyre JM, Pinkus GS, 
et al. Improved prognosis of diffuse histiocytic and undifferentiated lymphoma by use of high dose methotrexate alternating with standard agents (M-BACOD). F Clin Oncol 1983;1:91

28 Skarin AT, Canellos GP, Rosenthal DS, Case D, McIntyre J, Pinkus C, et al. Moderate dose methotrexate (m) combined with bleomycin (B), Adriamycin (A), cyclophosphamide $(\mathrm{C})$, Oncovin $(\mathrm{O})$, and dexamethasone (D), $\mathrm{m}$-BACOD is advanced diffuse histiocytic lymphoma (DHL) [abstract]. Proceedings of the American Society of Clinical Oncology 1983;2:220.

29 Longo DL, DeVita VT, Duffey PL, Wesley MN, Ihde DC, Hubbard SM, et al. Superiority of ProMACE-CytaBOM over ProMACE-MOPP in the et al. Supchority of Dre randomized trial. F Clin Oncol 1991;9:25.

large cell lymphoma. Ann Intern Med 1985:102:596.
31 Coiffier B, LePage E. Prognosis of aggressive lymphomas: a study of five prognostic models with patients included in the LNH-84 regimen. Blood 1989;74:558.

32 Shipp MA, Harrington DP, Klatt MK, Jochelson MS, Pinkus GS, Marshall $\mathrm{JL}$, el al. Identification of major prognostic subgroups of patients with large cell lymphoma treated with m-BACOD or M-BACOD. Ann Intern Med 1986;104:757.

33 Jagannath S, Velasquez WS, Tucker SL, Fuller LM, McLaughlin PW, Manning JT, et al. Tumor burden assessment and its implication for a prognostic model in advanced diffuse large cell lymphoma. 7 Clin Oncol 1986;4:859.

34 Hoskins PJ, Ng V, Spinelli J, Klimo P, Connors JM. Prognostic variables in patients with diffuse large-cell lymphoma treated with MACOP-B. fClin Oncol 1991;9:220.

\title{
Lesson of the Week
}

\section{Potentiation of aluminium absorption by effervescent analgesic tablets in a haemodialysis patient}

\author{
J Main, M K Ward
}

Gastrointestinal aluminium absorption is greatly increased by citrate, which may unknowingly be prescribed in effervescent or dispersible tablets
Renal Offices, Royal Victoria Infirmary, Newcastle upon Tyne NE1 4LP

$\mathrm{J}$ Main, senior registrar in nephrology

M K Ward, consultant nephrologist

Correspondence to: Dr Main.

BMY 1992;304:1686
It has recently been shown that in renal failure patients taking aluminium containing preparations as phosphate binders, concurrent administration of citrate enhances intestinal aluminium absorption.' This is an important interaction because of the acute and chronic effects of aluminium on brain and bone and the fairly common practice of prescribing citrate to renal failure patients either as a calcium salt or Shohl's solution. ${ }^{2-4}$ We report enhanced aluminium absorption due to concurrent administration of effervescent analgesics.

\section{Case history}

A 45 year old woman on home haemodialysis was on a regular treatment with aluminium hydroxide capsules $950 \mathrm{mg}$ thrice daily as a phosphate binding agent. Monthly checks were made of serum aluminium concentrations, which never exceeded $2 \cdot 5 \mu \mathrm{mol} / \mathrm{l}$. She developed ophthalmic herpes zoster and was treated with acyclovir tablets and a compound analgesic, co-codamol (paracetamol $500 \mathrm{mg}$, codeine $8 \mathrm{mg}$ ), up to six tablets daily. Ten days later routine blood testing revealed a sudden 10 -fold increase in serum aluminium concentration to $18.5 \mu \mathrm{mol} / \mathrm{l}$ (figure). Inquiry revealed that the co-codamol had been dispensed in effervescent form, each tablet containing $1.5 \mathrm{~g}$ sodium citrate. After stopping this the aluminium concentrations fell to

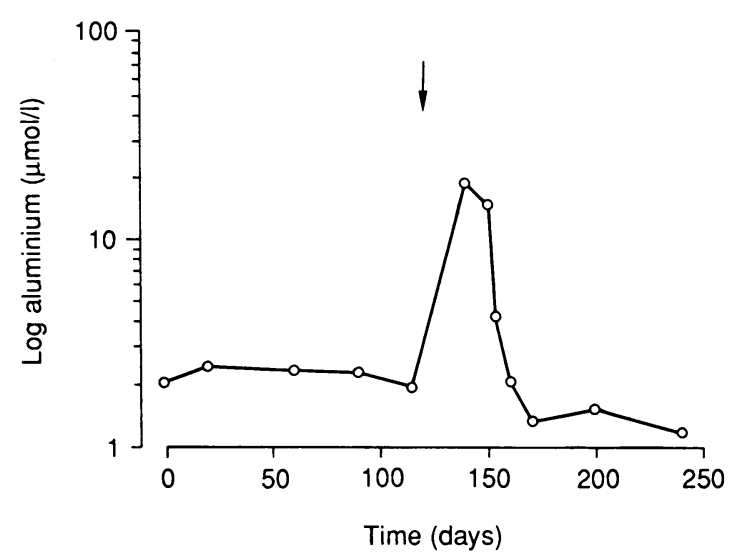

Change in serum aluminium concentration with time. Arrow indicates date of starting effervescent analgesic treatment acceptable levels over the next three weeks. The patient developed no symptoms or signs of acute aluminium toxicity.

\section{Discussion}

Increased serum aluminium concentrations and acute aluminium toxicity produced by the concurrent administration of aluminium salts and citrate containing compounds in patients with renal failure have recently been described. ${ }^{2-4}$ In these cases the citrate was given either to combat metabolic acidosis or as calcium citrate to treat renal bone disease. The increase in aluminium concentrations is due to enhanced gastrointestinal absorption mediated by citrate's properties of increasing aluminium solubility and opening gastrointestinal mucosal tight junctions.

These reports recommend that patients with renal failure taking aluminium compounds should not be prescribed citrate containing preparations. Our experience draws attention to the presence of citrate in a commonly used and widely available group of drugs-effervescent or dispersible analgesics. Such compounds can be bought without prescription. Clearly, it is important that renal patients taking aluminium containing compounds are not prescribed and do not self administer citrate based effervescent analgesics. The presence of citrate in these compounds is frequently omitted from descriptions of the drugs in both the British National Formulary and the Data Sheet Compendium. We suggest that when citrate is used in drug formulations it is clearly labelled to enable renal failure patients and those who prescribe for them to avoid such drugs if indicated.

The Committee on Safety of Medicines has been informed of this interaction.

1 Partridge NA, Regnier FE, White JL, Hem SL. Influence of dietary constituents on intestinal absorption of aluminium. Kidney Int 1989;35:1413-7.

2 Kirschbaum BB, Schoolwerth AC. Acute aluminium toxicity associated with oral citrate and aluminium-containing antacids. Am $\mathcal{F}$ Med Sci 1989;297:9-11.

3 Molitoris BA, Froment DH, Mackenzie TA, Huffer WH, Alfrey AC. Citrate: a major factor in the toxicity of orally administered aluminium compounds.

4 Nolin CR, Califano JR, Butzin CA. Influence of calcium acetate or calcium citrate on intestinal aluminium absorption. Kidney Int 1990;38:937-41.

(Accepted 27 September 1991) 